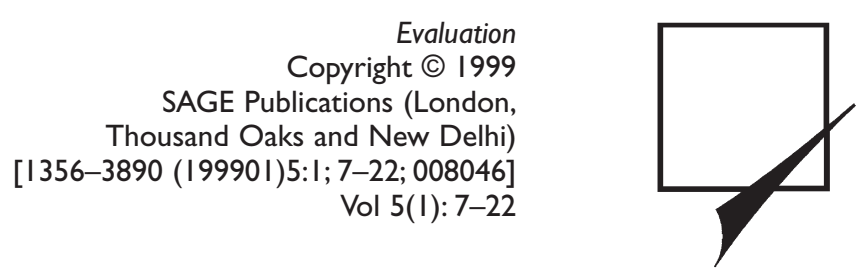

\title{
Towards an Economics of Evaluation
}

\author{
ROBERT PICCIOTTO \\ Operations Evaluations, The World Bank, Washington DC
}

This article probes the contrasting traditions of economics and evaluation and shows that intensified collaboration would benefit both professions. While evaluators have long been examining the impact of economic advice on public policy, economists have neglected evaluation both as a platform for testing economic policy hypotheses and as a topic for economic research in its own right. To encourage convergence between economics and evaluation, this article sketches the elements of an institutional economics of evaluation, considers the ongoing debate about the proper function of evaluation in society and presents cost benefit concepts and a supply demand framework to scrutinize the value and prospects of evaluation activities. Finally, it identifies performance measurement as a priority area for cooperation between evaluators and economists.

\section{Introduction}

Public policy is informed both by economics - the queen of the social sciences and by evaluation - the overarching meta-discipline. In support of policy reform and institutional change, both professions are grappling with the impact of globalization, technological upheavals and rising popular expectations. Decisionmakers need both professions to implement the 'new public management' principles taking root in the industrial democracies and incipient in reforming developing and transition economies (Mayne and Zapico-Goni, 1997). Economists are helping to redefine the role of government to make room for the market and the civil society. Evaluators are crafting performance indicators to help improve the workings of the state. But collaboration across disciplinary boundaries has been inhibited by cultural idiosyncrasies.

\section{The Two Cultures}

The utility maximizing individual (or firm) operating in a competitive environment is the intellectual starting point for economists while evaluators are typically concerned with the workings of public agencies. These distinctive orientations are reflected in contrasting professional methods. Economists concentrate on the 


\section{Evaluation 5(1)}

implications of neoclassical theory for policies and programs: they base their recommendations on predictive models or doctrinal considerations. By contrast, evaluators give a privileged role to empirical evidence and make selective use of social science techniques to assess policies and programs. In search of relevant policy recommendations, evaluators prize 'rich description' and manipulate masses of 'dirty' data, whereas economists are inclined to parsimony and limit data collection to the minimum needed to validate 'clean' models. Thus, economics and evaluation use different lenses to examine public policy and generate complementary analyses for use by policy makers.

These differences conceal a fundamental commonality of objectives. Both professions rely on theory and observation to explain social phenomena. Both seek to influence decision making through observation, description and prescription. For N. Gregory Mankiw (1998), 'when economists are trying to explain the world, they are scientists; when they are trying to improve it, they are policy makers'. The very same can be said of evaluators. According to Eleanor Chelimsky (1985), program evaluation is 'the application of systematic research methods to the assessment of program design, implementation and effectiveness'. The potential for effective cooperation between economists and evaluators has been demonstrated in the design of quasi-experimental and randomized control evaluations of government programs (Newman et al., 1994).

Evaluators have increased their scrutiny of the work of economists by identifying policy design and implementation errors. In the United States, the General Accounting Office routinely examines the efficacy of economic legislation and social policies (Havens, 1990). In Europe, evaluators are busy tackling the economic rationale of regional development schemes (Barbier and Simonin, 1997). At the World Bank, adjustment policies and programs, designed by economists, are frequent topics of evaluation studies (Jayarajah et al., 1996). As citizens' pressure for more accountable and responsive government intensifies, collaborative work between economists and evaluators is increasing in value.

The premise of this article is that evaluation studies are privileged instruments for assessing the value of economic policy advice. Equally, the economist's tool kit has the potential of enhancing the effectiveness of evaluation by challenging its methods, elucidating its structures and enriching its practices. Recently, economists have been giving more attention to the role of institutions in society. They have tackled everyday situations where transaction costs exist, market failures obtain or social norms constrain economic behaviour (Furubotn and Richter, 1991). Thus, the new institutionalists have analyzed sources of national wealth and tracked historical trends. As they turn their attention to decision making processes in organizations and government, they will be inevitably led to assess the role of evaluation as an institution.

\section{Evaluation as an Institution}

There is much of doctrinal debate among evaluators: the profession is still young and in rapid evolution. Inspired by the 'can do' public service ideals of a technocratic age, evaluation emerged three decades ago to support responsive and 
accountable government. Combining the principles of accounting and auditing with the insights of the social sciences and the operational relevance of system analysis, the new profession sought to meet a growing need for impartial, multidisciplinary, fact-based advice about 'what works and does not work'.

Evaluation is coming of age. It has expanded internationally; broadened the scope of its concerns; diversified its methodologies and secured substantial influence in public policy making. Yet, according to Eleanor Chelimsky and William R. Shadish (1997), evaluation is 'increasingly self-conscious about its own identity'. Because evaluation is 'practice driven' and shaped by diverse institutional contexts, instrumental definitions abound. Michael Scriven's (1991) concise definition of what evaluation is - 'the process of determining the merit, worth and value of things' - has not dampened debate about what evaluators do. Indeed, the history of evaluation has been characterized by vigorous debate and conflict followed by periodic attempts at synthesis and reconciliation.

In this spirit, this article proposes an objective examination of evaluation as an institution in terms of its economic rationale. Social institutions exist to help the agents in an economy solve certain recurrent problems. If so, evaluation has a single purpose - to help organizations and individuals achieve their objectives, based on societal values and norms. The acid test of its contribution to society is the incremental value of actual outcomes compared to the 'counterfactual' which would have materialized in the absence of evaluation.

Evaluation takes two major institutional forms. As a function attached to government, it is part of the societal ground rules which drive public choice or, given property rights, private choice. Or it may respond to the needs of individual private, voluntary, public and hybrid organizations. In both its macro-institutional and organizational incarnations, evaluation is embedded either in closed contractual arrangements (illuminated by agency theory) or in relational linkages (the domain of transaction cost theory).

From this perspective, the diversity of evaluation functions across countries and organizations is best understood in terms of the institutional pluralism which characterizes modern society. It is related to the wide range of relationships which link principals and agents within economies shaped by technological specialization, economies of scale and market volatility. In all cases, what the principal seeks is results and compliance with agreed standards. But the information available to the principal differs from the information available to agents. Evaluation arises out of this information asymmetry - and of the need to relate observed results and agents' behaviour. At its most basic level, evaluation provides the verification needed to 'make sure that the terms of the contract have been observed' (Coase, 1960).

Thus, independent evaluation is to the public sector what accounting and auditing are to the private sector. By providing standards for performance assessment and by attesting to the effectiveness of public services and public expenditures allocation, as well as through its role in 'enlightening' opinion makers (Weiss, 1998), evaluation is part of the overall governance framework. It fulfills Jeffrey Nugent's (1998) definition of an institution as 'a set of constraints that governs the behavioural relations among individuals or groups'. 


\section{Evaluation 5(1)}

But evaluation is also used within organizations where various agents (employees, suppliers, etc.) operate within rules and restraints set up by principals (senior executives, board of directors, etc.). Evaluation helps to design incentives frameworks to align agents' preference functions with organizational goals. It is needed for objective assessment of individual contributions to the overall result and as an antidote to opportunistic behaviour.

Of course, the behaviour of agents cannot be reduced to the fulfilment of precise contractual obligations. All the contingencies and uncertainties of real life cannot be anticipated in advance. Thus, many contracts are inevitably 'incomplete' and it is often necessary to rely on general policies and broad principles to provide participants in a collective enterprise with the flexibility they need to deal efficiently with unforeseen challenges. Here, independent evaluation may be valuable as a way of minimizing renegotiation of 'closed' contracts and associated litigation costs. And beyond its incentives effect at the level of individual contracts, evaluation contributes to the adaptive efficiency of society and organizations.

Evaluation also contributes to periodic changes in protocols, rules and practices in light of experience. According to Douglas North (1990):

The incentives embedded in the institutional framework direct the process of learning by doing and the development of tacit knowledge that will lead individuals in decision making processes to evolve systems gradually that are different from the ones that they had to begin with ... Adaptive efficiency, therefore, provides the incentives to encourage the development of decentralized decision making processes that will allow societies to maximize the efforts required to explore alternative ways of solving problems. We must also learn from failures, so that change will consist of the generation of organizational trials and the elimination of organizational errors.

The new institutional economics can illuminate the multiple roles of evaluation since, according to Buchanan (1975), 'economics comes closer to being a science of contract than a science of choice ... [on which account] the maximizer must be replaced by the arbitrator, the outsider who tries to work out compromises among conflicting claims'. For Oliver Williamson (1991), 'the object is less to resolve conflict in progress than it is to recognize potential conflict in advance and devise governance structures which forestall or attenuate it'. Evaluation is one such structure.

According to Eleanor Chelimsky (1997), three distinct purposes of evaluation can be discerned:

(a) evaluation for accountability (e.g. the measurement of results or efficiency); (b) evaluation for development (e.g. the provision of evaluative help to strengthen institutions); and (c) evaluation for knowledge (e.g. the acquisition of a more profound understanding in some specific areas or field).

From this perspective, whether it is part of the institutional environment or of an institutional arrangement, evaluation can be evaluated in terms of its contribution to three classes of social functions: (a) collective action; (b) participation; and (c) coordination. 
Collective action is needed to secure and implement a social or organizational consensus: evaluation for knowledge is especially relevant to this role. Participation provides connections between hierarchy and individuals: evaluation for development has a great deal to contribute to this function. Finally, coordination minimizes transaction costs: by enhancing accountability, evaluation contributes to this objective.

\section{Collective Action}

A collective action problem is a situation where all participants are better off if they cooperate even if it is not necessarily in the individual's perceived interest to do so. The allocation of public goods prevents such a problem since it cannot be adjudicated effectively through market mechanisms. Government policy making is also a collective action problem because, as demonstrated by Kenneth Arrow's impossibility theorem, aggregation of policy preferences cannot be done unambiguously to produce Pareto optimal outcomes.

Beneficiary surveys, rapid appraisal techniques, systematic use of focus groups and computer-based modes of public consultations have begun to influence evaluation products and processes. In situations where the decision making environment is not ripe for a traditional evaluation study - e.g. because there is no consensus on the standards for the conduct of an evaluation - a phased approach is needed starting with limited evaluations geared to principled policy dialogue and conflict resolution (IUCN and World Bank, 1997).

Evaluation can help overcome the information asymmetries and principalagent problems which plague public policy design and execution. But it is not a panacea. Not all evaluations facilitate collective action. Evaluation studies can be misused for tactical purposes, to gain time or to legitimize a partisan point of view. On the other hand, with expert facilitation, involvement of opposing interests in the evaluation process may create the conditions for a fruitful dialogue leading to cooperation. By inducing communication and clarifying the positions of stakeholders - and bringing impartial evidence to bear - complex public policy issues can be evaluated in a way which facilitates negotiation or mediation and ultimately helps to secure consensus among divergent interests.

\section{Participation}

Hierarchy is combined with participation wherever markets cannot be used to allocate scarce resources. In such a context, evaluation improves transparency and minimizes free-riding (Picciotto, 1994). Participation in evaluation is linked to greater devolution, decentralization and privatization. The advent of an activist civil society operating on a global scale has created a new kind of evaluation process closely connected to citizens' advocacy. In Karnataka, a private voluntary organization publicizes surveys of public service quality (Paul, 1995). Public agencies are increasingly seeking the views of users of their services to improve their workings while empowerment evaluation is being used to enhance selfdetermination, self-assessment and collaboration within groups (Fetterman, 1997). 
Participatory evaluation is often combined with independent evaluation. The two approaches are synergistic. The very process of exposing decision makers to information about the views of employees and clients tends to yield a deeper comprehension of the premises and shortcomings of public service programs. Conversely, independent evaluation can help to debunk misleading publicity by advocacy groups, or support their claims. In this way, it may help partisan advocates and/or critics of government programs to reassess their cherished beliefs and reach a deeper understanding of the issues.

What is the mix of participatory and independent evaluation most likely to contribute to better public policy in various institutional environments? Where complete contracts are appropriate, participatory evaluation can help overcome information asymmetries and reduce the resources needed to specify contractually all key elements of performance. Participatory evaluation may face constraints, however, where the transacting parties have widely divergent interests and perspectives. Especially if the contracting environment is volatile and uncertain, transactors in pursuit of informational and negotiating advantages over their partners may expend a lot of resources negotiating and monitoring one another.

In such circumstances, independent evaluation may help to mediate and adjust contractual agreements intentionally designed to be incomplete. This assumes, of course, that the transactors trust the independent evaluator more than they trust one another and/or that he or she can develop the information needed to reach a fair allocation of costs and risks at lower cost than the transactors on their own.

\section{Coordination Through Evaluation}

Similarly, evaluation can help to achieve effective coordination. The need for coordination arises from specialization, a prerequisite of productivity. Neoclassical markets coordinate producers' and consumers' actions, allocate resources according to comparative advantage and, in the process, maximize the utility of producers and consumers. Elsewhere (e.g. within the company or in the public sector) 'the visible hand of management replaces what Adam Smith referred to as the invisible hand of market forces' (Chandler, 1977). This is where evaluation comes in different flavours to deal with a variety of coordination problems.

Where decisions are urgent and require close synchronization, self-monitoring is the most appropriate. According to Charles F. Sabel (1994), social learning is best done through decentralized monitoring based on the Japanese 'just in time' mode of production. Such a system allows for instant and transparent identification of production weaknesses as they manifest themselves. It promotes cooperation and is the most effective way of improving coordination and ensuring high quality outcomes: it triggers remedial action by those closest to the action and requires a minimum of hierarchy. It reflects relational contracts between employees and management in an organizational context characterized by trust, clear decision rules and full commitment to excellence.

Where, on the other hand, little upward communication of local knowledge is needed and coherent action and limited tolerance for error are imperative, 
command and control systems require centralized evaluation which concentrates on assessing compliance with standards. In such environments, evaluation is routinely used by superiors to assess quality and to set incentives for employees so as to minimize principal-agent problems.

Whether in centralized or decentralized modes, utilization-based evaluation can generate high benefits for executives seeking to improve their performance - as well as the record of the private, public and voluntary organizations they lead. This, according to Evert Vedung (1997), is the domain of formative evaluation which puts a premium on 'speed and pertinence vis-a-vis a broad range of pressing issues' rather than 'on the development of new knowledge according to rigorous methodological standards' and may even 'obviate the possibility of careful research in the academic sense'.

In other situations, infusion of information from outside the organization is needed, and periodic adjustments in corporate strategies are called for by evolving markets and competitive pressures. This is where periodic, independent evaluation of policies and programs, reporting to the supreme authority, ensures appropriate alignment between strategy, the authorizing environment and core corporate competencies.

\section{Evaluation Supply and Demand}

Thus, there are highly diverse needs for evaluation which call for tailor-made solutions. On the supply side, the obstacles to a rapid expansion in evaluation activity are few. In a remarkably short time, professional foundations have been laid. There is a ready-made potential supply of evaluators in all the social sciences as well as in the auditing profession. Specialized training is available. A steady stream of publications and a regular cycle of professional meetings facilitate professional interchange. Formal associations and informal groupings, backed-up by electronic networks, connect evaluators across agencies, sectoral disciplines and national boundaries. Certification of evaluators is under consideration by the American Evaluation Association and its European and Australasian counterparts.

But this is not a field where Say's Law obtains: evaluation supply does not generate its own demand. Compared to the professions of auditing and economics, evaluation is still an infant industry. And it remains embattled and subject to undermining and capture even in countries and organizations where it has had a long history. As an ingredient of management consultancy services, evaluation is flourishing. But to the extent that it is a public good, it tends to be underproduced. Evaluation has the potential to help citizens overcome the information asymmetries and the high monitoring costs of programs which are of vital concern to their welfare. And there is little doubt that the public interest would be well served by the dissemination of reliable data and objective judgments about government policies and programs.

Yet, for reasons well articulated by public choice theorists, the needs of the many do not necessarily translate into effective demand or voluntary funding of evaluation services. Legislation mandating independent evaluation of public 


\section{Evaluation 5(1)}

sector programs is not widespread. Nor where it exists (e.g. in Colombia or Costa Rica) has it been implemented systematically. The disconnect between public need and actual demand for evaluation is a fit subject for economic research. The benefits of evaluation belong to large groups (citizens, consumers, etc.) which according to the logic of collective action formulated by Mancur Olson (1965) are at a disadvantage against vested interests usually represented by small and cohesive groups. One solution lies in generating countervailing pressures from the civil society. In some circumstances, small and nimble nongovernmental organizations can provide a wholesome counterweight to vested interests. In other circumstances, they act as vested interests themselves.

The fitful progress made in building evaluation capacity worldwide is more often due to exogenous pressures than to endogenous initiatives. The impetus for evaluation has often come from parliaments, supreme audit organizations, budget authorities or funding agencies. Internally, there are fears that budgetary allocations may be reduced as a result of evaluations; reluctance to share control over information flows; distrust about performance-based evaluations; etc. Citizen pressure is the ultimate source of legitimacy for aligning responsibility with authority through evaluation. But enlightened leadership is also a key ingredient.

The demand prospects for evaluation services are improving. The premise that institutions are the ultimate source of economic welfare has gained in acceptance, and global capital markets have become arbiters of national economic governance. Arbitrary behaviour by the state creates uncertainty and discourages investment and growth. With the spread of democratic government worldwide, dissatisfaction with state institutions is increasingly translated into political agitation and change. Institutional fundamentals are now perceived as equally important as policy fundamentals, and the balance between policy reform and institutional capacity is carefully weighed by investors and the international community in evaluating the prospects of national economies.

Policy distortions matter, to be sure, but without a basic institutional commitment to property rights, a sound and predictable judicial framework, economic agents will not invest and increase productivity (Chibber, 1998). Reduced opportunities for officials to act corruptly are created by cutting back on their discretionary authority, increasing competition and facilitating public exposure through the media. In this context, mechanisms that foster evaluation along with voice and partnerships in state activities can enhance the credibility and responsiveness of the public sector. Performance measurement and/or feedback mechanisms from the recipients of public services help to increase public service transparency and accountability.

Contestability for public service provision and government capacity to enter into formal contracts and institute cost-effective oversight mechanisms are additional ingredients of improved economic management. Enforcement of contracts for the delivery of services with easily specified outputs is far more effective than detailed controls over inputs and budget expenditures. Dissemination of service standards and civil service remuneration tied to results creates momentum for constructive change. Even in institutionally weak countries, impressive results can be achieved where public agencies are granted the autonomy, the 
management skills and the incentives framework needed to improve their performance (Pradhan, 1998).

\section{Benefits and Costs}

It should be clear by now that the need for evaluation is basic to the nature of public sector organizations. In the public sector, goods and services are produced through non-market cooperation among individuals working as teams, according to fixed protocols and with access to specialized information. There is no market test for such goods - or for the organization and processes which produce them. The reliable assessment of quality for public sector goods and services requires special arrangements, labelled evaluation.

Deeply embedded in human and social capital, evaluation is knowledge about knowledge. By providing transparency and improving accountability, evaluation can help improve the quality of public services and provide an antidote to vested interests. Nothing can more effectively deflate the self-serving claims of politicians and bureaucrats than a factual account of actual program results. Thus, evaluation can yield benefits well in excess of its direct costs (typically 1-3 percent of administrative costs) through wholesome effects on the productivity of expenditures and the responsiveness of the public organizations. But if evaluation is such a good use of resources, why isn't it more prevalent? In part this 'Chicago school' type of question is answered by public choice considerations.

But even if vested interests are overcome and evaluation gets established, there is no assurance that evaluation results will be put to work judiciously and effectively. It is axiomatic that evaluation only enhances the legitimacy of authority through improved accountability and/or decreases the likelihood of unnecessary error if it is actually used by decision makers to improve the quality of their decisions. Even when it is highly skilled in production and delivery, evaluation cannot guarantee follow-up action or well-directed utilization. The actual benefits derived from evaluation products are a function of the use made of them.

Thus, the worth of evaluation cannot be related wholly to the quality of its supply. Its value is related in significant part to management factors. Evaluation utilization is relatively high in organizations which practice quality management and seek reliable information about results and clients' satisfaction. In particular, within learning organizations, trust permeates relationships and keeps the transaction costs of evaluation low. In rigid, poorly managed organizations, on the other hand, evaluation is hardly used and can lead to costly interactions, if not 'cover ups' which damage credibility and undermine trust. In extreme cases, evaluation becomes vulnerable to capture. Hence, the paradox of low demand for evaluation in the very organizations which are in greatest need of it.

Finally, evaluation benefits also depend on supply factors. Evaluation can make things worse (Stiglitz, 1998) and this is why the first duty of the evaluator is to do no harm. Poorly designed evaluations can distort incentives. Where outcomes are difficult to measure, there is a temptation to use the most easily available indicators and they may not be the right ones. Performance may be measured according to process indicators which may have only a tangential or even perverse 


\section{Evaluation 5(1)}

impact on actual outcomes. Participatory evaluations may lead to wrong judgments, e.g. where survey participants are uninformed or biased.

Judging programs against pre-determined targets may give the wrong signals: the targets may be irrelevant, overambitious or exceedingly modest. This risk is widespread as goal-based methods are deeply rooted in evaluation practice. Without a connection to program objectives, evaluation would not be supportive of accountability and its value for organizational learning would be diminished. The credibility and fairness of evaluation hinges on carrying out fair and rigorous assessment of program goals. Still, it is not always feasible to assess the relevance of program objectives in terms of the 'counterfactual'. Thus, the temptation to use ready-made, control-oriented performance indicators is ever-present, with deleterious consequences for the incentives framework.

Trust in evaluation is critical for securing evaluation benefits. This underlies the imperative of professional excellence in program evaluation, especially with respect to the validity of causality attributions, i.e. proven linkages between program results, on the one hand, and policy design and performance factors, on the other. Evaluation differs from auditing to the precise extent that it subjects the goals and procedures to reach them as fit objects of scrutiny rather than as benchmarks. In effect, beyond its impact on incentives at the level of the individual civil servant, evaluation supports 'double loop' learning. It deals not only with compliance but also with the justification of organizational policies and the appropriateness of management practices.

Moral hazard may threaten the benefits and credibility of evaluation. Where evaluators are unprotected from intimidation or lack appropriate oversight, they may be tempted to provide misleading findings. Conversely, where evaluation results are used to reward or penalize employees in a simplistic fashion or to tarnish the reputation of senior officials who were not given the tools needed to achieve program results, reasonable risk taking may be inhibited. In effect, evaluation needs evaluation.

\section{Evaluating Evaluation}

Evaluation managers have the responsibility of adapting the product to the market. And there are circumstances where the market for evaluation is so poor that it is best not to promote it, lest it be misused and distorted to subordinate objectivity to the demands of the powerful. At the product level, evaluation managers should make explicit assessments of benefits and costs before authorizing an evaluation activity. For an evaluation to be carried out, its incremental benefits should be higher than its incremental costs.

First, the information gained through a retrospective evaluation should be relevant to current circumstances. Path dependence is never absolute and the past is not always prologue. Thus, the focus of evaluation should be directed to programs and practices which are still in place. Recommendations about program improvements should be made only if they flow logically from the evidence presented. Evaluation timing should be selected judiciously, as accuracy in evaluation results may involve tradeoffs in terms of timeliness: evaluations carried out 
many years after a program has reached maturity are more reliable since they offer the possibility of capturing the full impact of program actions 'on the ground'.

But the longer the time elapsed, the greater the costs associated with information retrieval and interpretation, the larger the chances of experience in the operating environment and the greater the threat to relevance. A mix of evaluation processes (ranging from evaluability assessments to monitoring reports and to retrospective evaluations and impact studies) may be needed to overcome this dilemma. Thus, an individual study may not be expected to meet the combined tests of relevance and accuracy in such a way as to trigger appropriate decisions.

Next, evaluations should be subject to the test of efficacy. Evaluation results must be credible in order to be acted upon. The French have a saying about two ways of being wrong - one of which is being right too early. To go against common misconceptions, especially if they are fortified by self-interest, implies a threshold of proof much higher for an independent evaluation than for a self-evaluation. Beyond the rigour of the evidence, clarity in presentation; credibility of evaluation methods and fairness in the processes used to validate findings - and allow the subjects of the evaluation to record their comments as part of the evaluation - all contribute to the likelihood of adoption of evaluation findings.

Finally, the efficiency of the evaluation process needs critical examination. The information gathered (and the judgments reached) should, of course, add value to the stock of knowledge available to program managers. But other things being equal they should also do so at a lower cost than would be feasible through selfevaluation. This is a demanding test since evaluators are often at an informational disadvantage vis-a-vis program managers and need their cooperation to overcome it. In order to make a difference, independent evaluators must have access to best practice data and demonstrate superior analytical skills and experienced judgment.

How much evaluation is enough? Diminishing returns materialize as the absorptive capacity of the organization gets saturated. Just as too little evaluation may be damaging to an organization, excessive recourse to evaluation may lead to unnecessary transaction costs and lead to information overload or the undermining of management by the higher levels of authority to which evaluation reports. Mindful of this risk, Kenneth Arrow (1974) recommends suitable restraint in the scope and reach of evaluation and notes that 'significant resources' should be used 'only for significant questions', e.g. evaluation should be 'intermittent' and activated 'only when performance is sufficiently degraded from expectations' or 'take the form of review and deeper study of a random sample of decisions'. On the other hand, Arrow notes the value of evaluation in terms of disseminating information which is not available to or used by the authority because of the 'tendency to filter information in accordance with one's preconceptions'.

\section{The Economics of Performance Measurement}

The need for evaluation has grown due to public pressure for efficient, responsive and accountable government. According to Kathryn Newcomer (1997), 'an 


\section{Evaluation 5(1)}

unprecedented challenge to the evaluation profession has arisen from the increasing demand for documentation of results of public and nonprofit programs'. Many initiatives have emerged around the world to meet a growing public demand for objective description and scoring of program results in the public and voluntary sectors. They combine the lessons of prior efforts to assess the quality of public services through modern planning and budgeting processes with the experience recently gained in the restructuring efforts of private corporations facing global competitive pressures.

Performance measurement is a visible component of the public sector reform movement which is spreading throughout the world in response to a wave of democratization, decentralization and devolution of government services. It is a major tool of the 'new public management' movement and it aims to link wellselected measures of service delivery to policy assessment, strategy development, goal setting, resource allocation, program monitoring and evaluation of managerial and staff performance. A distinctive feature of performance measurement is its association with results-based management processes in which civil service employees as well as beneficiaries of public services participate both at the goal setting and performance assessment stages.

There are widespread expectations that performance measurement in the public sector is feasible and useful. Increasingly, score cards of indicators are constructed by public agencies to support resource requests and to convince voters of the value of government services. Considerable efforts are underway to involve politicians, employees and service beneficiaries in the selection of indicators. Performance measurement has become an integral part of program management and public relations in many agencies. Linkages between performance measurement, resource allocation processes and civil service remuneration systems are being explored. Much greater use of customer feedback, performance-based partnerships and outcome-based performance contracts has accompanied performance measurement (Hatry, 1997).

Typically, a 'logical framework' of input, output, outcome and impact indicators is compiled. The focus of performance measurement is on results, i.e. on the last three indicators. This is in contrast to traditional accounting controls which concentrate on inputs; on budget indicators which connect resource use to output measures; and on auditing results which seek to assess whether funds were used for the purposes intended and in compliance with approved policies and procedures. Results-based management focuses on the quality of service delivery and on the satisfaction of stakeholders. It creates new incentives for improved management and it is probably here to stay.

The problem lies not in the content of the new approach but in the difficulty of implementing it effectively and meaningfully. Effective management of public policies requires a full understanding of the linkages between inputs, outputs, outcomes and impacts. Most public programs are called upon to satisfy a wide range of objectives. These may be in conflict with one another and call for tradeoffs at the margin. The result of public policies may be influenced by exogenous factors so that accountability for results is shared among a wide range of public agencies and partners. Independent reviews of performance measurement systems in the 
United States suggest slow and partial implementation despite sustained efforts by the executive branch under the Government Performance and Results Act of 1993.

Paradoxically, neither economists nor evaluation professionals have been called upon systematically to support performance measurement efforts. Yet, without effective connection to sound management and independent evaluation, performance measurement could turn into a fad. There is a serious risk of backlash as the public becomes aware that the simple compilation of results indicators says little about the relevance of the outcomes achieved, the efficiency of resource use or the accountability of the public agency for the results achieved. Just as auditing is needed to ensure that financial accounts are truthful, independent verification of the scope and content of performance measurement is critical to its long-term credibility.

In the absence of professionally selected and carefully evaluated indicators, moral hazard may intervene and efforts may be directed to the satisfaction of measured goals rather than genuine progress towards achievement of service quality. For example, a poorly designed results-based contract between the Paris municipality and a private company charged with the removal of illegally parked vehicles had the unintended effect of inducing a shift of vehicle removal efforts to the suburbs whereas the highest benefits would have been obtained by focusing vehicle removal within the congested downtown (Mounier, 1995).

Thus, the opportunity cost of neglecting to involve professional economists and evaluators may be high, not least because their absence would hinder systematic knowledge management. Many public programs are social experiments which would benefit from objective review, based on which lessons can be validated for use in the design of future programs. Reliable documentation of 'what works' and 'what to watch for' is critical to social learning. Evaluating public sector innovations and sharing the results are a public good. They need to be nurtured. In this context, the decline of cost benefit analysis as a standard evaluation instrument emerges as a worrisome indicator of the gap which still divides evaluators from economists.

\section{Towards an Economics of Evaluation}

At the societal level, evaluation provides a way to overcome information asymmetries between the people as principal and the state as agent. Within organizations, evaluation is a feature of quality management and a complement to performance measurement. It enriches the accountability framework provided by generally accepted standards of financial auditing. It helps to improve incentives facing managers and employees. Where it operates at arm's length, it helps improve public oversight, strengthen the credibility of economic governance and create learning opportunities for policy making.

To 'get the institutions right' means combating government failure. Evaluation helps to resolve collective action dilemmas and to improve connectivity between the citizenry and the government. It takes many institutional forms, shaped by different requirements at various levels of the social hierarchy - ranging from 


\section{Evaluation 5(1)}

improved accountability through coordination; institutional development through consensus building and improved collective action through knowledge development and participation. These diverse functions call for the right mix among three kinds of evaluation approaches.

First is independent evaluation - accountability to a central body. Second is self-evaluation - the use of evaluation as an aid to public sector managers operating within a decentralized public sector. Third is participatory evaluation involving a variety of stakeholders. Over the long run, these three approaches are complementary, even synergistic. But at any point in time, trade-offs may be necessary, and appropriate sequencing strategies must be designed to build evaluation capacity to reflect initial conditions and make use of available opportunities for constructive change.

To illuminate such choices, the structure and the processes of evaluation need more systematic attention by institutional economists. Various kinds of evaluation have different impacts on the costs associated with search and information, bargaining, decision, monitoring and enforcement. The reduction of such transaction costs attributable to evaluation - both in the short run and, through adaptive efficiency, in the longer run - represents the benefits of investment in evaluation. Such benefits must be weighed against the direct costs involved in setting up and operating the evaluation function.

The realization that there are many alternative approaches to evaluation, and that they can be scrutinized in cost benefit terms, would help demystify doctrinal debates between utilization-based and arm's length evaluation; quantitative and qualitative evaluation; independent and self evaluation etc. And it would throw light on the protocols which govern evaluation practice, help modernize the function to meet the demands of performance measurement, and accelerate progress towards the development of generally accepted standards for evaluation. Beyond this, a rapprochement between the evaluation and economics professions would help fulfil the promise of the 'new public management' movement, for the benefit of all.

\section{References}

Arrow, K. (1974) The Limits of Organization. New York and London: W. W. Norton and Company.

Barbier, J. C. and B. Simonin (1997) 'European Social Programmes: Can Evaluation of Implementation Increase the Appropriateness of the Findings?', Evaluation 3(4): 391-407.

Buchanan, J. (1975) 'A Contractarian Paradigm for Applying Economic Theory', American Economic Review 65: 225-30.

Chandler, A. (1977) The Visible Man: The Managerial Revolution in American Business. Cambridge, MA: Belknap Press, Harvard University Press.

Chelimsky, E. (ed.) (1985) Program Evaluation: Patterns and Directions. Washington, DC: American Society for Public Administration.

Chelimsky, E. (1997) 'The Coming Transformations in Evaluation', in E. Chelimsky and W. R. Shadish (eds) Evaluation for the 21st Century. London: Sage Publications. 
Chelimsky, E. and W. R. Shadish (eds) (1997) Evaluation for the 21st Century. London: Sage Publications.

Chibber, A. (1998) 'Institutions, Policies, and Development Outcomes', in Evaluation and Development: The Institutional Dimension. Rutgers: Transaction Publishers.

Coase, R. H. (1960) 'The Problem of Social Cost', Journal of Law and Economics 3: 1-44.

Fetterman, D. (1997) 'Empowerment Evaluation and Accreditation in Higher Education', in E. Chelimsky and W. R. Shadish (eds) Evaluation for the 21st Century. London: Sage Publications.

Furubotn, E. G. and R. Richter (1991) 'The New Institutional Economics: An Assessment', The New Institutional Economics. Tubingen: J. C. B. Mohr (Paul Siebeck).

Hatry, H. (1997) Where the Rubber Meets the Road: Performance Measurement for State and Local Public Agencies, New Directions for Evaluation: Using Performance Measurement to Improve Public and Non-Profit Programs, No. 75. San Francisco, CA: Jossey-Bass.

Havens, H. S. (1990) The Evolution of the General Accounting Office: From Voucher Audits to Program Evaluations. Washington, DC: General Accounting Office.

IUCN and the World Bank (1997) Large Dams: Learning from the Past, Looking at the Future. Washington, DC: IUCN, Gland, Switzerland and Cambridge, UK: The World Bank Group.

Jayarajah, C., W. Branson and B. Sen (1996) Social Dimensions of Adjustment, World Bank Experience, 1980-93. Washington, DC: The World Bank, Operations Evaluation Department.

Mankiw, N. G. (1998) Principles of Economics. Orlando, FL: The Dryden Press, Harcourt Brace Jovanovich, College Publishers.

Mayne, J. and E. Zapico-Goni (eds) (1997) Monitoring Performance in the Public Sector: Future Directions from International Experience. New Brunswick and London: Transaction Publishers.

Mounier, E. (1995) 'Comments on "Evaluating Public Services: A Case Study on Bangalore, India"', in Evaluation and Development: Proceedings of the 1994 World Bank Conference. Washington, DC: The World Bank.

Newcomer, K. (1997) Using Performance Measurement to Improve Public and Nonprofit Programs, New Directions for Program Evaluation, No. 75. San Francisco, CA: JosseyBass.

Newman, J., L. Rawlings and P. Gerteler (1994) 'Using Randomized Control Designs in Evaluating Social Sector Programs in Developing Countries', The World Bank Research Observer 9(2).

North, D. (1990) Institutions, Institutional Change, and Economic Performance. Cambridge: Cambridge University Press.

Nugent, J. (1998) 'Institutions, Markets, and Development Outcomes', in Evaluation and Development: The Institutional Dimension. Rutgers: Transaction Publishers.

Olson, M. (1965) The Logic of Collective Action. Cambridge, MA: Harvard University Press.

Paul, S. (1995) 'Evaluating Public Services: A Case Study on Bangalore, India', in Evaluation and Development: Proceedings of the 1994 World Bank Conference. Washington, DC: The World Bank.

Picciotto, R. (1994) 'Visibility and Disappointment: The New Role of Development Evaluation', in L. Rodwin and D. A. Schön (eds) Rethinking the Development Experience. Washington, DC: The Brookings Institution.

Pradhan, S. (1998) 'Reinvigorating State Institutions', in Evaluation and Development: The Institutional Dimension. Rutgers: Transaction Publishers. 


\section{Evaluation 5(1)}

Sabel, C. F. (1994) 'Learning by Monitoring: The Institutions of Economic Development', in Neil J. Smelser and Richard Swedberg (eds) The Handbook of Economic Sociology. Princeton, NJ: Princeton University Press.

Scriven, M. (1991) Evaluation Thesaurus. Newbury Park, CA: Sage Publications.

Stiglitz, J. (1998) 'Evaluation as an Incentive Instrument', in Evaluation and Development: The Institutional Dimension. Rutgers: Transaction Publishers.

Vedung, E. (1997) Public Policy and Program Evaluation. New Brunswick and London: Transaction Publishers.

Weiss, C. (1998) Evaluation Research: Methods of Assessing Program Effectiveness. Englewood Cliffs, NJ: Prentice-Hall.

Williamson, O. E. (1991) 'Economic Institutions: Spontaneous and Intentional Governance', Journal of Law, Economics, and Organization 7: 159-87.

ROBERT PICCIOTTO is Director-General, Operations Evaluations at the World Bank in Washington, DC. Please address correspondence to: The World Bank, I8I8 H Street, N.W.Washington, Washington DC 20433, USA.

[email: rpicciotto@worldbank.org] 